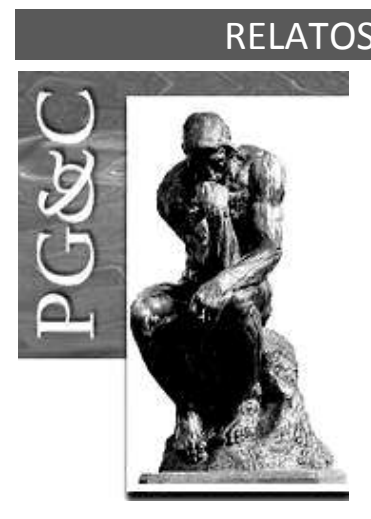

\title{
DESENVOLVIMENTO DE UM FRAMEWORK PARA AVALIAÇÃO DE FATORES CRÍTICOS DE SUCESSO DE PARQUES CIENTÍFICOS E TECNOLÓGICOS
}

\author{
André Luís Sena Nascimento \\ Mestre em Administração de Empresas pela Universidade Pontifícia \\ Católica do Rio Grande do Sul, Brasil. Engenheiro Sênior de Sistemas no \\ ramo financeiro, Bélgica. \\ E-mail: andre.sena@gmail.com \\ Ana Roberta Sousa Mota \\ Doutora em Informação e Comunicação em Plataformas Digitais pela \\ Universidade do Porto, Portugal. Bibliotecária da Universidade Federal da \\ Paraíba, Brasil. \\ E-mail: anarobertamota@gmail.com
}

\begin{abstract}
Resumo
Os parques científicos e tecnológicos (PCT) representam um ambiente de cooperação e integração que estimula a transferência de conhecimento e tecnologia entre seus stakeholders, por meio de atividades de pesquisa e inovação. Portanto, um parque científico e tecnológico deve criar mecanismos de incentivo à colaboração e à inovação, no sentido de estimular a competitividade dos stakeholders que coabitam naquele espaço. Metodologias e ferramentas devem estar disponíveis aos gestores de parques para atingir esse objetivo. Recorrendo-se à literatura, identificou-se uma lacuna referente à falta de tais mecanismos para auxiliar os processos de identificação e avaliação dos fatores críticos de sucesso (FCS) de PCT. Dessa maneira, este artigo detalha como ocorreu o desenvolvimento de tal ferramenta (framework) e a propõe como um mecanismo de auxílio à gestão de PCT. Portanto, por meio da utilização do framework proposto, gestores de parques podem entender como tornar o ecossistema de um parque científico e tecnológico mais competitivo.
\end{abstract}

Palavras-chave: Parque científico e tecnológico. Fatores críticos de sucesso. Framework.

\section{FRAMEWORK DEVELOPMENT FOR EVALUATION OF CRITICAL SUCCESS FACTORS OF SCIENTIFIC AND TECHNOLOGICAL PARKS}

\begin{abstract}
The science and technology parks (STP) represent an environment of cooperation and integration that encourage knowledge and technology transfer among its stakeholders through research and innovation activities. Therefore, a STP should create mechanisms to encourage collaboration and innovation, in order to promote the competitiveness of the stakeholders that cohabit in that space. Methodologies and tools should be available to managers of the parks to achieve this goal. Referring to the literature, a gap was identified regarding the lack of such mechanisms to assist the processes of identification and evaluation of critical success factors (CSF). In this way, this article details how the development of such tool (framework) occurred and proposes it as a mechanism for STP management. Therefore, through the use of the proposed framework managers of the parks is able to understand how to make the ecosystem of STP more competitive.
\end{abstract}

Keywords: Science and technology park. Critical success factors. Framework.

Perspectivas em Gestão \& Conhecimento, João Pessoa, v. 9, n. 2, p. 128-152, maio/ago. 2019. DOI: http://dx.doi.org/10.21714/2236-417X2019v9n2p128

http://periodicos.ufpb.br/ojs2/index.php/pgc. ISSN: 2236-417X. Publicação sob Licença (cc) EY-NC-ND 


\section{INTRODUÇÃO}

A competitividade organizacional é conceituada de diferentes formas pelos estudiosos do tema e não existe um consenso em relação à sua definição. Ferraz, Kupfer e Haguenauer (1997) definem competitividade como a capacidade que permite as organizações implementarem estratégias para conseguir e manter uma posição sustentável no mercado de forma duradoura. Zairi (1997) afirma que competitividade é o resultado de um planejamento inteligente contínuo, que ocorre por meio de análises do entendimento das necessidades dos clientes. Outra linha de pensamento afirma que a competitividade deve ser analisada por fatores internos, como, por exemplo, entender a organização de uma maneira sistêmica e o segmento de mercado ao qual ela pertence, e por fatores externos, como a economia nacional e internacional (EISENHARDT; SANTOS, 2002).

Outras análises também sustentam a competitividade organizacional e introduzem o estudo dos recursos organizacionais, como forma de aumentar a competitividade das organizações (SANCHEZ, 2004). Essa abordagem teórica chamada de Visão Baseada em Recursos (VBR) estabelece que a vantagem competitiva das organizações acontece em virtude dos recursos internos, os quais estão disponíveis nas organizações e pelas combinações que podem ser arranjadas por meio de tais recursos (PENROSE, 1959; WERNERFELT, 1984; BARNEY, 1991). Segundo Penrose (1959), os recursos devem ser combinados com as capacidades presentes nas firmas para a geração da vantagem competitiva e a criação de valor econômico. Já Wernerfelt (1984) afirma que os competidores que primeiro chegam ao mercado garantem a vantagem competitiva e têm habilidade de fazer novas combinações com os recursos disponíveis, mantendo-os em mercados poucos explorados.

Segundo Barney (1991), a vantagem competitiva acontece quando uma organização implementa uma estratégia que não seja conhecida por nenhum potencial competidor e que tenha duração de um intervalo de tempo mínimo. O pesquisador introduziu o conceito de vantagem competitiva sustentável, que se refere à capacidade de uma firma em manter a sua estratégia organizacional, mesmo com os esforços de outras organizações em tentar imitar a vantagem competitiva da primeira. Para isso, é necessário criar estratégias de longa duração, responder eficientemente às oportunidades criadas pelo mercado, neutralizar as ameaças externas dos competidores e chegar, tão logo que possível, ao mercado (BARNEY, 1991).

Por outro lado, Penrose (1959) afirma que a vantagem competitiva das organizações tem curta duração, já que as mesmas sofrem de imitação e que, para aumentar tal vantagem, é preciso fazer novas combinações com os recursos disponíveis, renovar as capacidades, diversificar e expandir o conhecimento primário e técnico em áreas especializadas. Com isso, a pesquisadora contribuiu para a "Teoria de Crescimento da Firma", que diz que, para uma firma crescer de modo efetivo, deve haver o balanço entre a taxa de crescimento e a capacidade de gerenciar recursos. Para se atingir esse patamar, é vital ter a disponibilidade de talentos técnicos e gerenciais. Se os recursos forem subaproveitados e desconectados, pode acontecer a perda da vantagem competitiva (PENROSE, 1959).

Wernerfelt (1984) complementa essa teoria e afirma que os recursos devem ser efetivamente utilizados para que uma organização maximize seus lucros e abranja mais mercados. Além disso, novos recursos e produtos devem ser desenvolvidos e incorporados na estratégia organizacional (WERNERFELT, 1984). Ainda segundo Barney (1991), os recursos têm quatro características básicas para o sucesso das firmas: (1) serem heterogêneos, ou seja, terem diferentes habilidades e conhecimentos para serem usados nas diferentes estratégias das empresas; (2) raros, ou seja, não devem estar presentes nos competidores; (3) valiosos, ou seja, devem implementar com sucesso e rapidez as estratégias das organizações (HELFAT; PETERAF, 2003); e (4) não terem mobilidade, ou seja, eles devem permanecer na organização para manter a vantagem competitiva. Ainda na visão de Barney (1991), cada organização

Perspectivas em Gestão \& Conhecimento, João Pessoa, v. 9, n. 2, p. 128-152, maio/ago. 2019. 
implementa uma utilização diferenciada dos recursos, uma vez que existem diferenças de alocação, desenvolvimento e combinação dos mesmos. Logo, a maneira mais eficiente de usálos é garantir e sustentar a sua vantagem competitiva.

Apesar das várias contribuições de pesquisadores sobre o tema de vantagem competitiva, estudos da análise da competitividade são notoriamente incompletos, uma vez que as organizações consideram as idiossincrasias passadas de indicadores e não as relações causais da competitividade (FERRAZ; KUPFER; HAGUENAUER, 1997). É necessário interpretar a competitividade organizacional de uma forma dinâmica, ou seja, como um aspecto externo, relacionado a um padrão de concorrência que realimenta as estratégias organizacionais adotadas (FERRAZ; KUPFER; HAGUENAUER, 1997). Esse padrão representa os Fatores Críticos de Sucesso (FCS) de um segmento de mercado. Portanto, identificar tais fatores torna-se primordial para a competitividade de uma organização, já que ela é a condição para a existência e o sucesso organizacional. A troca de conhecimento e tecnologias, aprendizado, inovação e formação de um "conhecimento comum" são, igualmente, importantes para a conquista da vantagem competitiva, que acontece na relação entre duas ou mais organizações (SLUYTIS et al., 2010). Este artigo utiliza a definição de FCS como um ou mais fatores competitivos que utilizam os recursos disponíveis para o aumento da competitividade de uma organização (ROCKART, 1979; GRUNERT; ELLEGAARD, 1992; BROTHERTON; SHAW, 1996).

Um exemplo desse cenário é o que acontece nos Parques Científicos e Tecnológicos (PCT) - um tipo de arranjo interorganizacional. De modo geral, pode-se afirmar que parque científico e tecnológico é um empreendimento de base científico-tecnológica, que é formado por empresas, instituições de ensino e pesquisa e/ou universidades, cuja operação se baseia em atividades de fomento à pesquisa e à inovação (ANPROTEC, 2002; UNESCO, 2015; IASP, 2015; AURP, 2016). O estudo em PCT vem sendo largamente debatido e a quantidade de trabalhos relacionados tem crescido substancialmente, atraindo considerável atenção na última década (VÁSQUEZ-URRIAGO et al., 2014).

Este artigo detalha o desenvolvimento de um framework como forma de contribuir para os desafios apresentados e o sugere como mecanismo de identificação e avaliação dos FCS de PCT pelos gestores. Ter informações disponíveis sobre os FCS de um parque é de vital importância para mapear ações que devem ser planejadas, no sentido de fomentar colaborações, integrações e competitividade do parque e de seus stakeholders (VIAL; OLMOS, 2014).

\section{METODOLOGIA}

Este estudo foi desenvolvido por meio do método de pesquisa qualitativo, com utilização de técnicas de coleta de dados, como entrevistas semiestruturadas, descrições e observações, e análise de dados do conteúdo coletado (SAMPIERI, 2006). O estudo abrangeu caráter exploratório e consistiu na realização de nove entrevistas com especialistas acadêmicos e de PCT, cuja finalidade era desenvolver e refinar os componentes do framework proposto. Em cada fase e etapa, os componentes sofreram alterações e refinamentos sugeridos pelos entrevistados e baseados na referência teórica utilizada.

A construção do framework proposto foi desenvolvida em quatro fases. Na primeira fase foram definidos os aspectos metodológicos do método de pesquisa, além da elaboração de três componentes iniciais do framework. O primeiro deles faz referência aos fatores competitivos de PCT, que correspondem a uma lista de itens classificada em diferentes categorias. Cada item representa um potencial fator crítico de sucesso, que pode, ou não, ser observável no parque em análise (passo 1 para identificação dos FCS). Utilizou-se a análise categorial do tipo temática, pois as categorias do componente foram obtidas pelas operações de desmembramento do texto, que emergiram da bibliografia utilizada e da reunião de itens

Perspectivas em Gestão \& Conhecimento, João Pessoa, v. 9, n. 2, p. 128-152, maio/ago. 2019. 
representativos, os quais se relacionavam com cada uma delas (BARDIN, 2006). Uma vez identificados, os fatores competitivos, que são observáveis em um parque, foram analisados pelo segundo componente, o fluxograma de identificação de FCS de PCT. Assume-se que um fator competitivo observável será um fator crítico de sucesso se todas as perguntas do fluxograma forem respondidas com resposta "SIM". Quando obtida uma resposta "NÃO", o processo de análise passa a ser direcionado para outro fator competitivo observável do parque. Um ou mais fatores competitivos podem ser combinados para que um fator crítico de sucesso de PCT seja identificado. Já o terceiro componente diz respeito aos parâmetros, que representam as características que podem ser observadas nos FCS identificados. Eles serviram como base para o processo de avaliação desses fatores.

A segunda fase foi composta por três etapas. A primeira etapa realizou-se com um especialista acadêmico e teve o objetivo de fazer um teste inicial do framework para verificar seu entendimento e se seus componentes poderiam atender aos objetivos propostos. Os critérios de seleção para o especialista foram: ter titulação mínima de doutorado e linha de pesquisa relacionada aos parques e competitividade organizacional; apresentar projetos em desenvolvimento com os temas mencionados; e estar acessível, manifestando interesse em participar da entrevista. A segunda etapa, realizada com três especialistas acadêmicos, teve como objetivo refinar os componentes propostos de acordo com as percepções dos mesmos. Os mesmos critérios de seleção foram adotados nessa etapa. A terceira etapa, com quatro especialistas de parques, teve como objetivo identificar FCS de PCT e verificar se os parâmetros propostos poderiam avaliar os FCS identificados. Os componentes propostos sofreram alterações devido às percepções dos especialistas, mas conseguiram atingir os objetivos definidos nessa etapa da pesquisa. Em relação à escolha dos candidatos para essa etapa, os critérios observados foram: ocupar cargo de gestor ou similar de um parque; ter atuado em processos que envolvem o parque e interações com a universidade, empresas ou instituições públicas; e ser acessível, mostrando interesse em participar da pesquisa.

Após os refinamentos dos especialistas, oito parâmetros restaram para avaliar os FCS de PCT. São eles: (1) distinção; (2) inimitabilidade; (3) durabilidade; (4) flexibilidade; (5) velocidade; (6) combinação; (7) inovação; e (8) conhecimento. Após o estabelecimento desses parâmetros, desenvolveram-se as escalas de análise para a terceira fase. Tais escalas tiveram o objetivo de apontar o nível observável dos parâmetros nos FCS identificados, realizando, assim, a sua avaliação. Elas estão mencionadas na seção de análise de resultados deste artigo. Com efeito, os processos que fazem parte do framework proposto (identificar e avaliar os FCS de PCT) estavam definidos. A Figura 1 ilustra esses processos, assim como os componentes que fazem parte deles.

Figura 1 - Componentes estruturais do framework proposto

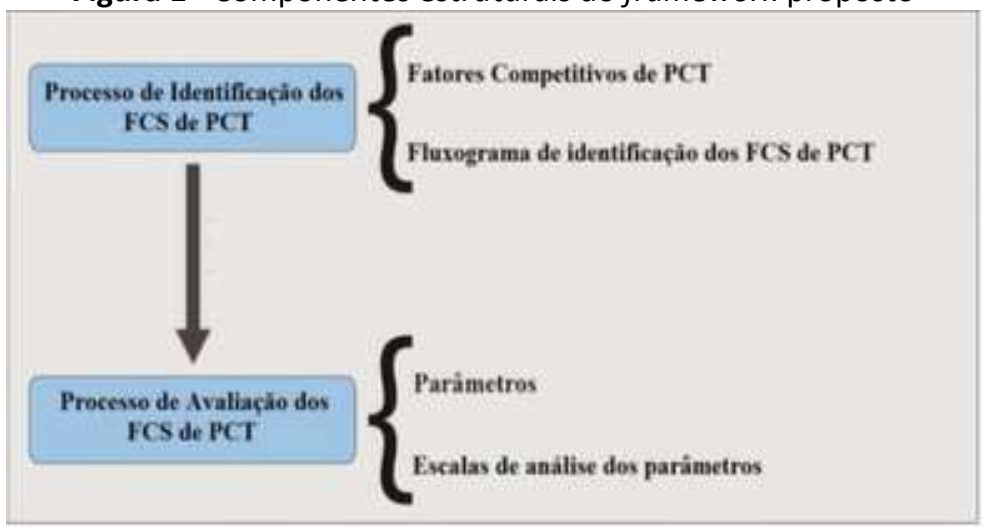

Fonte: Dados da pesquisa (2016)

Perspectivas em Gestão \& Conhecimento, João Pessoa, v. 9, n. 2, p. 128-152, maio/ago. 2019. 
A terceira fase da pesquisa compreendeu três etapas de refinamentos, aplicados aos componentes do framework. A primeira etapa objetivou a realização de um teste com a versão inicial do framework sugerido, conduzida por um especialista acadêmico. Uma vez analisadas e aplicadas as sugestões desse especialista, passou-se para a segunda etapa dessa fase, conduzida por especialistas acadêmicos, e a terceira etapa por especialistas de parques.

Embora todos os componentes tenham sido desenvolvidos, o último deles ainda precisava ser avaliado, bem como o framework de uma maneira geral. Portanto, na quarta fase, realizou-se o refinamento das escalas de análise pelo especialista. Julgou-se que somente um especialista de parque era necessário, pois os componentes já haviam passado por refinamentos anteriores. $\mathrm{O}$ objetivo dessa fase era verificar se o framework conseguiria atingir os objetivos propostos, que era identificar e avaliar os FCS de PCT. Os mesmos critérios de escolha do entrevistado foram observados nessa fase da pesquisa.

Ao final dessa fase, os FCS de PCT foram identificados e avaliados por meio da utilização do framework proposto. Esse fato indicou que o mesmo poderia atingir os objetivos propostos. A seguir, demonstra-se o desenvolvimento do framework.

\section{PARQUES CIENTíFICOS E TECNOLÓGICOS}

Os PCT vêm recebendo crescente atenção de governantes como sendo um ponto central para o desenvolvimento da economia e políticas regionais (LINK; SCOTT, 2007). Os parques, também, vêm despertando interesse tanto da academia quanto do meio empresarial e o número de publicações do tema tem crescido substancialmente na última década (VÁSQUEZ-URRIAGO et al., 2014). Muitos gestores empresariais têm percebido a importância de estarem inseridos dentro dos parques, pois estes possibilitam a colaboração e a integração com outras empresas e universidades por meio da transferência de conhecimento, tecnologia e atividades de pesquisa e inovação (BOLTON, 1997; ETZKOWITZ,1998; ANPROTEC, 2002; UNESCO, 2015; IASP, 2015; AURP, 2016), bem como maior competitividade para as empresas que estão inseridas dentro deles (VARGAS; RECH; SANTOS, 2016).

$\mathrm{Na}$ literatura acadêmica, verificam-se alguns conceitos em relação à definição de parque (VEDOVELLO; JUDICE; MACULAN, 2006). Autores e órgãos de parques classificam os parques em: parque científico, onde notoriamente se observa o desenvolvimento de empresas tecnológicas (BOLTON, 1997); parque tecnológico, onde se destacam o empreendedorismo, a capacitação, a produção empresarial e comercial (ANPROTEC, 2002); e parque científico e tecnológico, marcado pela presença de uma universidade que atua como fonte e troca do conhecimento, integrando todos os seus stakeholders (SPOLIDORO; AUDY, 2008).

Os primeiros PCT surgiram nas décadas de 1970-80, nos países desenvolvidos, como uma resposta para a recessão econômica e industrial, a fim de revitalizar a política industrial e promover a sinergia e a inovação de forma sistemática (VEDOVELLO; JUDICE; MACULAN, 2006). A partir da década de 90 , houve uma considerável expansão de iniciativas de parques no Brasil (ZOUAIN, 2003). Alguns programas governamentais foram criados para estimular o desenvolvimento tecnológico brasileiro a partir da integração de universidades, empresas e institutos de pesquisa, auxiliando o processo de inovação no Brasil (ZOUAIN, 2003).

No entanto, o Brasil ainda não tem modelos claros e definidos, práticas consagradas para a viabilização, implantação e gerenciamento de parques (GARGIONE; LOURENÇÃO, 2005). Isso acontece em função da ausência de parâmetros padronizados de avaliação de parques, tanto na fase de implantação como na fase de desenvolvimento e operação (VEDOVELLO; JUDICE; MACULAN, 2006). Um mecanismo para avaliação de parques poderia ser utilizado como forma de justificar investimentos públicos, conhecendo, antecipadamente, os benefícios que os mesmos poderiam gerar.

Perspectivas em Gestão \& Conhecimento, João Pessoa, v. 9, n. 2, p. 128-152, maio/ago. 2019. 
Considerando a literatura de competitividade organizacional, este artigo reuniu apontamentos/questionamentos dos autores no que se refere à identificação das competências organizacionais, conforme vê-se no Quadro 1. O conteúdo coletado foi utilizado como base para a construção de um fluxograma de identificação de FCS de PCT, adaptado ao contexto de parques.

Quadro 1 - Apontamentos para identificar FCS de PCT

\begin{tabular}{|l|c|}
\hline \multicolumn{1}{|c|}{ Apontamentos / Questionamentos } & Autor(es) \\
\hline (1) verificar se o fator competitivo gera valor para os stakeholders; & \\
(2) verificar se o fator competitivo é criado a partir do uso estratégico dos \\
recursos disponíveis; & Prahalad e Hamel \\
(3) verificar se o fator competitivo provê um potencial acesso para uma grande \\
variedade de mercados; \\
(4) verificar se o fator competitivo contribui de maneira significante para os \\
stakeholders. & \\
\hline (1) o que um parque científico e tecnológico sabe fazer bem? & \\
(2) o que um parque científico e tecnológico sabe fazer bem para estar presente \\
em uma unidade de negócio ou fazer parte dele como um todo? \\
(3) o fator competitivo promove competitividade para o parque? \\
(4) o fator competitivo promove competitividade durável? \\
(5) os processos do fator competitivo são relevantes para o mercado atual? & \\
\hline (1) o fator competitivo deve ser sustentado por um ou mais recursos & \\
importantes para o parque; & \\
(2) o fator competitivo deve representar valor para os stakeholders; & \\
(3) o fator competitivo deve ser fonte de competitividade. & Mills et al. (2002). \\
\hline (1) o fator competitivo deve criar valor para os stakeholders; & \\
(2) o fator competitivo deve gerar benefícios para os stakeholders. & Hitt, Ireland e \\
\hline
\end{tabular}

Fonte: elaborado pelos autores com base na literatura consultada (2016)

No que se refere à verificação do processo de avaliação dos FCS de PCT, reuniu-se um conjunto de características semelhantes, observadas nos FCS das organizações (MINTZBERG, 2003), com base na literatura científica sobre competitividade organizacional, adaptada à utilização no contexto de parques, conforme listado no Quadro 2.

Quadro 2 - Parâmetros iniciais para avaliar FCS de PCT

\begin{tabular}{|l|l|}
\hline \multicolumn{1}{|c|}{ Parâmetros e objetivos } & \multicolumn{1}{c|}{ Autor(es) } \\
\hline $\begin{array}{l}\text { Valor: analisa o grau em que o fator crítico de } \\
\text { sucesso aumenta a competitividade de um parque e } \\
\text { de seus stakeholders. }\end{array}$ & $\begin{array}{l}\text { Prahalad \& Hamel (1990); Petts (1997); } \\
\text { Javidan (1998); Helfat e Peteraf (2003) e } \\
\text { Sanchez (2004). }\end{array}$ \\
\hline $\begin{array}{l}\text { Exclusividade: analisa se o fator crítico de sucesso } \\
\text { está presente de modo único no parque. }\end{array}$ & $\begin{array}{l}\text { Prahalad e Hamel (1990); Barney (1991); } \\
\text { Heene e Sanchez (1997); Hitt, Ireland e } \\
\text { Hoskisson (2009) e Petts (1997). }\end{array}$ \\
\hline $\begin{array}{l}\text { Durabilidade: analisa o quão durável é um fator } \\
\text { crítico de sucesso no sentido de manter a } \\
\text { competitividade de um parque. }\end{array}$ & $\begin{array}{l}\text { Barney (1991); Petts (1997) e Ljungquist } \\
\text { (2007). }\end{array}$ \\
\hline $\begin{array}{l}\text { Imitabilidade: analisa o grau de facilidade } \\
\text { enfrentado ao tentar imitar um fator crítico de } \\
\text { sucesso de um parque. }\end{array}$ & $\begin{array}{l}\text { Barney (1991); Prahalad e Hamel (1990); } \\
\text { Petts (1997); Hitt, Ireland e Hoskisson (2009) } \\
\text { e Heene \& Sanchez (1997). }\end{array}$ \\
\hline $\begin{array}{l}\text { Renovação: analisa o grau de dificuldade para } \\
\text { conseguir renovar um fator crítico de sucesso à } \\
\text { medida que surgem novas demandas dos } \\
\text { stakeholders e do mercado. }\end{array}$ & $\begin{array}{l}\text { Penrose (1959); Petts (1997); Teece, Pisano, } \\
\text { \& Shuen (1997); Javidan (1998) e Mills et al. } \\
\text { (2002). }\end{array}$ \\
\hline \begin{tabular}{l} 
Inovação: analisa a capacidade do fator crítico de \\
\hline
\end{tabular} & Penrose (1959); Prahalad e Hamel (1990); \\
\hline
\end{tabular}

Perspectivas em Gestão \& Conhecimento, João Pessoa, v. 9, n. 2, p. 128-152, maio/ago. 2019. 


\begin{tabular}{|c|c|}
\hline $\begin{array}{l}\text { sucesso em contribuir para a criação de novos } \\
\text { produtos, tecnologias e articulações com os } \\
\text { stakeholders de um parque. }\end{array}$ & $\begin{array}{l}\text { Mills et al. (2002); Petts (1997); Teece; } \\
\text { Pisano; Shuen (1997) e Danneels (2002). }\end{array}$ \\
\hline $\begin{array}{l}\text { Raridade: analisa o quão raro é o fator crítico de } \\
\text { sucesso e a não presença dele em outros parques. }\end{array}$ & $\begin{array}{l}\text { Barney (1991); Hitt, Ireland e Hoskisson } \\
\text { (2009); Heene e Sanchez (1997); Mills et al. } \\
\text { (2002) e Campbell (2008). }\end{array}$ \\
\hline $\begin{array}{l}\text { Flexibilidade: analisa o grau do fator crítico de } \\
\text { sucesso em adaptar-se às novas necessidades dos } \\
\text { stakeholders, do mercado e de novas tecnologias. }\end{array}$ & $\begin{array}{l}\text { Hafeez, Zhang; Malak (2002) e Sanchez } \\
\text { (2004). }\end{array}$ \\
\hline $\begin{array}{l}\text { Combinação: analisa quanto um fator crítico de } \\
\text { sucesso pode ser combinado com outros ou com } \\
\text { recursos disponíveis para atender a uma nova } \\
\text { demanda do mercado. }\end{array}$ & $\begin{array}{l}\text { Teece; Pisano; Shuen (1997); Mills et al. } \\
\text { (2002) e Ruas (2005). }\end{array}$ \\
\hline $\begin{array}{l}\text { Cognição: analisa quanto um fator crítico de sucesso } \\
\text { pode ser adquirido pelo processo de aquisição do } \\
\text { conhecimento que ocorre por meio de percepção, } \\
\text { atenção, associação, memória, raciocínio, juízo, } \\
\text { imaginação, pensamento e linguagem. }\end{array}$ & $\begin{array}{l}\text { Sanchez (2004); Leite; Porsse (2005) e Chen; } \\
\text { Chang (2010). }\end{array}$ \\
\hline $\begin{array}{l}\text { Substituição: analisa quanto um fator crítico de } \\
\text { sucesso pode ser substituído por outro no intuito de } \\
\text { proporcionar mais competitividade para os } \\
\text { stakeholders de um parque. }\end{array}$ & Petts (1997) e Heene e Sanchez (1997). \\
\hline
\end{tabular}

Fonte: elaborado pelos autores com base na literatura consultada (2016)

\section{DESENVOLVIMENTO DO FRAMEWORK PARA AVALIAÇÃO DE FCS DE PCT}

\subsection{Refinamentos e revisões: interação com especialistas}

Os primeiros refinamentos e revisões realizados no framework para avaliar FCS de PCT foram feitos junto a um professor da Pontifícia Universidade Católica do Rio Grande do Sul (PUCRS), com experiência na área de estratégia organizacional e de PCT. Essa etapa da pesquisa teve como objetivo fazer uma avaliação inicial nos componentes do framework antes da sua utilização de fato (WITT, 1973).

Com relação ao primeiro componente do framework proposto - fatores competitivos de PCT -, sugeriram-se mudanças textuais, as quais foram analisadas e incorporadas para torná-lo mais compreensível, como: na categoria serviços técnicos especializados, substituiuse o item "disponibilidade de mão de obra especializada" pelo item "disponibilidade de acesso à mão de obra especializada"; e na categoria mercadológicos, substituiu-se o item "oportunidade de negócio e conhecimento sobre o mercado" pelo item "oferta de oportunidade de negócio e oferta de conhecimento sobre o mercado", respectivamente. Os outros itens do componente permaneceram inalterados devido à compreensão do especialista entrevistado.

Uma mudança incorporada ao componente foi a redução em um dos questionamentos para identificar os FCS. O componente verificava se uma habilidade dos PCT contribuía para os benefícios das empresas instaladas e se tal habilidade representava valor para as mesmas, por meio de dois questionamentos distintos. Analisando alguns conceitos sobre a relação custobenefício, verificou-se que o comentário do entrevistado fazia sentido e era compartilhado por alguns autores. Então, o questionamento em torno da verificação da habilidade contribuía para os benefícios das empresas instaladas, e, por isso, foram removidos do fluxograma para identificar os FCS. O especialista ainda sugeriu trocar a expressão "[...] ou representa o parque como um todo" por "[...] nas atividades do parque" na pergunta do fluxograma "Essa

Perspectivas em Gestão \& Conhecimento, João Pessoa, v. 9, n. 2, p. 128-152, maio/ago. 2019. 
habilidade está presente ou representa o parque como um todo?". De acordo com o especialista, o entendimento da pergunta ficaria melhor se não perdesse de vista o objetivo original do questionamento.

A sugestão foi incorporada, visto que o objetivo dessa fase da pesquisa era tornar os componentes do framework mais compreensíveis (WITT, 1973). Para as outras perguntas do componente, percebeu-se uma sintonia entre o entrevistado e os autores de estratégia organizacional utilizados na revisão bibliográfica. $O$ especialista ainda apontou a importância de verificar se um fator competitivo (potencial fator crítico de sucesso) possuía relevância no contexto de parques, se era sustentado por recursos importantes do mesmo e se gerava valor para as empresas instaladas.

Em relação ao terceiro componente do framework proposto - parâmetros para avaliar os FCS -, algumas alterações foram realizadas. A primeira delas referiu-se ao parâmetro cognição. Recorrendo-se à literatura, observou-se o objetivo do parâmetro, que consistia em analisar quanto um fator crítico de sucesso podia ser adquirido pelo processo de aquisição do conhecimento, obtido por meio da percepção, associação, memória, juízo, imaginação, pensamento e linguagem. Apesar de os pesquisadores Cheng e Chang (2010) afirmarem que uma parcela dos FCS é adquirida por processos cognitivos, fazer a mensuração desse parâmetro e aplicá-lo no contexto de parques tornava-se uma atividade inviável. Diante dos aspectos observados, decidiu-se pela remoção do parâmetro cognição e adoção do parâmetro desenvolvimento, que analisa o tempo necessário para um fator crítico de sucesso ser adquirido pelo processo de aquisição do conhecimento. Esse parâmetro é factível de mensuração no contexto de parques. Ainda em relação aos parâmetros, outro comentário feito nessa etapa do artigo referiu-se à sua utilização. $O$ entrevistado atentou para o uso padronizado dos parâmetros, já imaginando a utilização das escalas de análise empregadas posteriormente.

Na visão do entrevistado, os parâmetros deveriam ser construídos de uma maneira padronizada, ou seja, a partir de uma escala crescente em relação à presença observável do mesmo nos FCS e à geração de valor para os parques. Este artigo adotou esse comportamento para todos os parâmetros sugeridos. Por essa razão, o parâmetro imitabilidade foi trocado por inimitabilidade, significando que quanto mais inimitável, mais maduro o fator crítico de sucesso está.

Todos os parâmetros, com exceção do parâmetro cognição, poderiam ser aplicados no contexto de parques para avaliá-los, conforme o entrevistado. Portanto, os outros parâmetros propostos valor, exclusividade, raridade, durabilidade, renovação, flexibilidade, substituição, combinação e inovação representaram uma sintonia entre a percepção do especialista acadêmico e os autores consultados.

Após a verificação, refinamento e revisão sugeridos pelo especialista com experiência na área de estratégia organizacional e de parques, detalham-se as análises desenvolvidas a partir da visão de três especialistas acadêmicos.

Em relação ao componente fatores competitivos de PCT, nenhuma categoria foi adicionada ou removida. Entretanto, os especialistas observaram alguns itens que poderiam deixar o componente mais abrangente. A primeira sugestão foi a inclusão do item "infraestrutura física para a instalação das empresas", na categoria infraestrutura. Sugeriu-se, também, a inclusão dos itens: "presença da diversidade de empresas no parque e ambiente propício para a interação entre pessoas e empresas", na categoria ambiente de inovação e empreendedorismo. Outro item observado foi o fato de ser um canal para a internacionalização de empresas, na categoria mercadológicos. Para os especialistas, um parque realiza acordos internacionais com universidades, institutos de ensino e pesquisa e outros parques. Além de conseguir inserir empresas e pessoas no mercado internacional. Em virtude da análise de informações de um parque (Tecnopuc, 2015) e da observação dos

Perspectivas em Gestão \& Conhecimento, João Pessoa, v. 9, n. 2, p. 128-152, maio/ago. 2019. 
especialistas, o item foi incorporado à categoria. Constatou-se um entendimento dos entrevistados em relação aos outros itens e categorias do componente FCS de PCT e, por isso, eles foram mantidos.

Em relação ao fluxograma de identificação de FCS de PCT, uma importante observação foi feita por um especialista acadêmico:

As suas perguntas do roteiro de identificação dos fatores críticos devem ser associadas aos fatores competitivos de parque. Esses fatores têm que conduzir a identificação. (...) Pergunte ao gestor onde estão as forças e as fraquezas que respondem pelos fatores competitivos do parque (especialista acadêmico 2, 2016).

Depois de analisar as conexões entre os dois primeiros componentes do framework proposto, observou-se que o comentário do especialista era pertinente. Havia uma lacuna entre eles e os questionamentos poderiam ser gerados quando o framework fosse aplicado em gestores de parques. Portanto, optou-se pela adição desses questionamentos para reduzir essas lacunas e estreitar a conexão entre os componentes, tornando eficaz o processo de identificação de FCS de PCT. Logo, foram adicionadas as perguntas iniciais no fluxograma: "Como se faz a gestão de cada categoria de fator crítico do parque? Existem práticas, processos e rotinas definidos? Existe algum fator competitivo representado por elas?". Substituindo a pergunta inicial do fluxograma: "O que um parque como instituição sabe fazer bem?".

Apesar de ser sugestão de um dos autores pesquisados, para Javidan (1998), essa troca permitiu uma conexão entre os componentes elencados, sem perder a ideia central indicada pelo autor. Outra sugestão dos especialistas buscou trocar o questionamento "o fator competitivo está presente nas atividades do parque?" por "o fator competitivo é responsável pela mobilização de recursos/habilidades do parque?". Para os especialistas, o questionamento facilitaria a identificação de fatores competitivos de PCT e não perderia o seu objetivo inicial. Constatou-se, também, que o questionamento proposto é sustentado pelos autores de estratégia corporativa consultados. Portanto, a sugestão foi incorporada.

Finalmente, um especialista observou que os questionamentos do fluxograma estavam ora analisando os parques em relação aos outros parques, ora focando ações do parque para atrair novas empresas. Na visão do entrevistado:

Pelas suas perguntas, percebe-se que há dois tipos de questionamentos que você está fazendo aqui: aspectos externos e internos ao parque. O primeiro é o parque se diferenciando em relação a outros parques e o segundo representado pelo engajamento das empresas para manter o parque competitivo. Enquanto você pensa num ambiente interno, você está pensando em um ambiente de colaboração. Quando você pensa no parque em ser competitivo no sentido de esse parque tem uma melhor visibilidade, as empresas vão poder ter uma inserção internacional melhor, vão poder captar novos mercados, nesse caso você está pensando em competição: as empresas do parque se unindo para competir. Tem dois movimentos interessantes no parque que envolvem fatores críticos de sucesso distintos (especialista acadêmico 3, 2016).

O comentário do especialista foi pertinente e poderia contribuir para a melhoria do entendimento do processo de identificação dos FCS. Logo, foi feito um remodelamento na ordem das perguntas do fluxograma, começando pelos questionamentos sobre os aspectos externos ao parque e depois sobre aspectos internos ao mesmo. O fluxograma de identificação

Perspectivas em Gestão \& Conhecimento, João Pessoa, v. 9, n. 2, p. 128-152, maio/ago. 2019. 
de FCS de PCT seguiu a seguinte ordem de questionamentos: (1) O fator competitivo é responsável pela mobilização de recursos/habilidades do parque?; (2) O fator competitivo possui relevância no mercado atual de parques?; (3) O fator competitivo é sustentado por um ou mais recursos importantes do parque?; (4) O fator competitivo é fonte de atração para empresas candidatas a se instalarem no parque?; (5) O fator competitivo representa valor para as empresas instaladas no parque?; e (6) O fator competitivo é um fator de atração durável para as empresas instaladas no parque?.

Quanto aos parâmetros para avaliar os FCS, um dos especialistas acadêmicos sugeriu substituir os parâmetros raridade e exclusividade pelo parâmetro distinção. Recordando os objetivos do parâmetro raridade, os quais analisam o quão raro é um fator crítico de sucesso em relação a outros parques, e do parâmetro exclusividade, que analisam o quanto um fator crítico de sucesso está presente, de um modo exclusivo, no parque, e verificando-se o depoimento do especialista, percebeu-se que a análise do aspecto de distinção do fator crítico de sucesso faria mais sentido no contexto de parques. Além disso, um fator crítico de sucesso distintivo pode ser mensurado por uma escala de análise. Portanto, a sugestão do especialista foi incorporada ao framework. Outra observação dos especialistas foi substituir os parâmetros renovação e flexibilidade pelo parâmetro adaptabilidade.

O objetivo do parâmetro renovação é analisar o grau de facilidade do parque na renovação de um fator crítico de sucesso quando surgem novas demandas das empresas e do mercado. Já o objetivo do parâmetro flexibilidade é analisar a facilidade do fator crítico de sucesso ao atender às novas demandas das empresas e do mercado. Ao analisar os objetivos dos parâmetros, identificou-se uma semelhança que foi realçada pelos depoimentos dos especialistas. Além disso, constatou-se que os parâmetros poderiam ser trocados, sem perder o objetivo inicial definido pelos autores consultados. Nessa perspectiva, os parâmetros renovação e flexibilidade foram substituídos por adaptabilidade, sobretudo por apresentar mais sentido no contexto de utilização.

Outra observação percebida refere-se à mensuração dos parâmetros. Como mencionado anteriormente, quanto maior a presença observável dos parâmetros nos FCS mais valor eles geram. $O$ parâmetro desenvolvimento estava divergindo dessa padronização. Por essa razão, o parâmetro foi alterado para rapidez, de modo a seguir o padrão adotado. 0 objetivo desse parâmetro é analisar o tempo necessário para o parque adquirir um fator crítico de sucesso que ainda não possui. Logo, quanto mais rapidez tiver para fazer isso, mais competitivo o parque será. Percebeu-se uma sintonia dos entrevistados em relação aos parâmetros valor, inimitabilidade, durabilidade, substituição, combinação e inovação. Então, os mesmos foram mantidos.

Para compreender, de fato, as características dos parques, realizaram-se entrevistas com quatro especialistas de variadas regiões do estado do Rio Grande do Sul. Em relação ao primeiro componente, um especialista apontou para a categoria infraestrutura, a qual é, sem dúvida, um fator importante de um parque para as empresas se estabelecerem. Entretanto, as discussões recentes apontam que outro aspecto tão relevante quanto esse corresponde aos ambientes distribuídos, que devem ter conexão com a gestão do parque.

Ao analisar informações sobre parques, percebe-se que alguns deles apresentam infraestrutura territorial distribuída e não concentrada em uma localidade geográfica. Como esse item representa um aspecto de parque, além de ser relevante na visão do entrevistado, ele foi incorporado ao framework. Ainda nessa categoria, um especialista apontou um item de relevante que não estava coberto pelo instrumento. $O$ item se refere aos ambientes compartilhados de integração e de qualificação, favorecendo a difusão e troca de conhecimento entre os stakeholders do parque. De acordo com a experiência do especialista, esse aspecto diferencia os parques.

Perspectivas em Gestão \& Conhecimento, João Pessoa, v. 9, n. 2, p. 128-152, maio/ago. 2019. 
A Anprotec (2002), lasp (2015) e Unesco (2015) também apontam para a importância desse item nos parques. Conforme esses órgãos, oferecer um local para a capacitação de pessoas e das empresas, bem como um ambiente colaborativo, diferencia um parque. Por essa razão, o item foi incorporado ao componente. Na categoria ambiente de inovação e empreendedorismo, algumas pequenas alterações foram feitas, como, por exemplo, o acréscimo da presença de incubadoras ou aceleradoras e não só das empresas incubadas, como estava representado anteriormente, mas de espaços de coworking. Os itens foram contemplados, já que, além dos especialistas consultados, Zouain (2003) e Bigliardi et al. (2006) também apontam a importância desses elementos nos parques.

$\mathrm{Na}$ categoria de gestão e governança do parque, um entrevistado afirmou que a maioria dos parques do Brasil não disponibiliza um conselho de gestores, mas sim de uma gestão executiva formada apenas pelos gestores do parque. Apresentar conselho de gestores é um segundo passo, após a gestão executiva ser formada. $O$ entrevistado faz parte da gestão executiva do parque e, na sua visão, "O mais importante para um parque é ter uma gestão executiva. O conselho de gestores é um passo mais adiante, um segundo estágio de evolução. A gestão executiva é mais importante" (especialista de parque 1, 2016).

$\mathrm{O}$ instrumento contemplava somente o conselho de gestores. No entanto, por ser uma característica de alguns parques brasileiros, como por exemplo, o TECNOPUC, o item foi incorporado ao instrumento para aumentar o seu grau de abrangência.

Já na categoria de fatores econômicos e financeiros, um especialista de parque, após ler todos os itens dessa categoria, afirmou faltar um item importante para representá-la, que seria a flexibilidade na modelagem econômico-financeira para atração de investimentos. Ter essa característica no parque em que ele atua pode representar toda a diferença. 0 depoimento do especialista aponta que um parque deve apresentar um modelo de flexibilidade econômico-financeira, já que o papel do mesmo é gerenciar o fluxo de conhecimento e tecnologia entre universidades, instituições de pesquisa e desenvolvimento, empresas e mercados, conforme aponta a lasp (2015). Percebe-se que a característica pode ser contemplada no contexto de parques, visto que são ambientes que compreendem empresas de diversos segmentos de mercado.

$\mathrm{Na}$ categoria de serviços técnicos especializados, dois dos quatro especialistas de parque afirmaram faltar um item importante na categoria. Segundo eles, a mentoria, diferentemente do coaching, deveria estar representada pelos serviços técnicos oferecidos pelo parque. Analisando os depoimentos dos especialistas e levando-se em consideração o posicionamento de Gargione (2011) que aponta para a importância desse fator, nota-se que disponibilizar esse tipo de serviço é importante para as empresas instaladas que estão começando a se desenvolver, como as incubadas e as startups. Portanto, o item foi incorporado ao componente.

$\mathrm{Na}$ categoria mercadológicos, um especialista de parque mencionou que o item "presença de mercado consumidor local de fácil acesso" não representava uma responsabilidade do parque. $O$ especialista sugeriu que o parque deve disponibilizar serviços de acesso aos mercados, principalmente para empresas que estão em fase de desenvolvimento. Analisando a sugestão do especialista, constatou-se que ela é pertinente. Não é responsabilidade de um parque apresentar mercado consumidor local e, sim, disponibilizar meios, principalmente para as empresas que estão começando a se desenvolver, o que é muito mais coerente e representativo para um parque. Devido a esses fatores, o item foi incorporado. Ainda na categoria mercadológicos, dois especialistas mencionaram que um parque, além de fomentar as relações entre as empresas e a universidade, deve estabelecer relações entre eles para que haja cooperação entre as empresas de diferentes parques. Logo, julgou-se uma observação pertinente para o ambiente de parques, visto que a cooperação e colaboração são aspectos relevantes nesses ecossistemas (ANPROTEC, 2002; UNESCO, 2015;

Perspectivas em Gestão \& Conhecimento, João Pessoa, v. 9, n. 2, p. 128-152, maio/ago. 2019. 
IASP, 2015). Alguns parques estabelecem esse tipo de relação e isso os diferencia. 0 item foi incorporado ao componente. Constatou-se um entendimento dos entrevistados em relação aos outros itens das categorias mencionadas acima e sobre as categorias interação universidade-empresa-governo e aspectos comportamentais e pessoais. Por esse motivo, eles foram mantidos.

Em relação ao componente fluxograma de identificação de FCS de PCT, um dos especialistas sugeriu substituir a expressão "mercado" por "ecossistema" no seguinte questionamento: "o fator competitivo possui relevância no mercado atual de parques?" Para o entrevistado:

No contexto de parques, não se utiliza "mercado". Os gestores dos parques não vão entender o que você está perguntando. Troca a palavra "mercado" por "ecossistema". Mercado é venda e produto. Isso não acontece nos parques dessa forma (especialista de parque 1, 2016).

Observou-se que a expressão "mercado" teve origem no contexto de estratégia organizacional, em que o componente fluxograma de identificação de FCS de PCT foi construído. Como o objetivo desta pesquisa consiste em propor um framework para parques, percebeu-se que a expressão ecossistema representa o contexto estudado e, por isso, decidiuse incorporá-lo. Verificou-se uma concordância dos especialistas em relação às outras perguntas do componente, mostrando um alinhamento entre eles e os autores utilizados para a construção do fluxograma. Além disso, os FCS foram identificados por meio do fluxograma, indicando que este poderia atingir os objetivos definidos.

No que tange aos parâmetros que foram mostrados para os especialistas de parques, foram feitas algumas sugestões no sentido de combinar alguns parâmetros de forma a melhorar o entendimento do instrumento para avaliar os FCS de parques. O especialista de parque 1 sugeriu combinar os parâmetros adaptabilidade, combinação e substituição, e criar um parâmetro chamado flexibilidade.

De acordo com o especialista de parque 2, o parâmetro combinação se aplica ao contexto de parques e representa o dinamismo que o mesmo tem de apresentar frente às demandas do mercado e dos clientes. Segundo ele, o parâmetro deveria ser mantido. Entretanto, os parâmetros adaptabilidade e substituição poderiam ser combinados para o parâmetro flexibilidade.

O especialista de parque 3 também concorda que o parâmetro combinação é importante, pois potencializa os FCS necessários de um parque. Por isso, ele deveria ser mantido.

Ao relembrar os objetivos dos parâmetros, percebe-se que a combinação analisa a facilidade de o fator crítico de sucesso ser combinado com outros para atender às novas demandas das empresas e do mercado; adaptabilidade analisa a capacidade do fator crítico de sucesso em se adaptar frente às novas demandas das empresas e do mercado; substituição analisa o quanto um fator crítico de sucesso pode ser substituído por outro. Como dois especialistas de parques realçaram a importância do parâmetro combinação, optou-se por manter esse parâmetro, visto que a maioria dos especialistas de parques apontou relevantes argumentos para mantê-lo, como potencializar as vantagens do parque e atrair novas empresas. Entretanto, dois especialistas indicaram a junção dos parâmetros adaptabilidade e substituição, bem como a criação de um outro nome para flexibilidade. Eles argumentaram que flexibilidade é um termo mais usado no contexto de parques do que adaptabilidade. 0 conceito de adaptabilidade poderia se manter, mas substituir o nome do parâmetro para flexibilidade representaria com mais legitimidade o instrumento. Portanto, optou-se por

Perspectivas em Gestão \& Conhecimento, João Pessoa, v. 9, n. 2, p. 128-152, maio/ago. 2019. 
seguir a orientação dos especialistas no intuito de elaborar um componente que consiga avaliar os FCS de PCT.

Em relação ao parâmetro rapidez, dois dos quatro especialistas de parques afirmaram que o parâmetro mais adequado ao contexto seria velocidade, em virtude de representar um fator competitivo em potencial e poder ser um fator crítico de sucesso. Para estar alinhado aos depoimentos dos especialistas, e sem perder o objetivo do parâmetro original rapidez, o nome foi alterado para velocidade. Finalmente, o especialista de parque 3 fez uma consistente observação, pois ainda estava faltando um parâmetro para avaliar o fluxo de trocas de informações entre os atores de um parque. Segundo o entrevistado, nenhum parâmetro cobria essa característica, tendo em vista que ele é vital para um parque. Ele mesmo sugeriu um nome para o parâmetro: conhecimento.

Apesar de somente um especialista de parque realçar a falta do parâmetro conhecimento, optou-se por criá-lo. $\mathrm{O}$ argumento do especialista fez sentido, pois analisar o fluxo de informações entre os atores de um parque é um objetivo importante para sua gestão. Além disso, autores da estratégia organizacional, como Prahalad e Hamel (1990) e Javidan (1998), assim como a Anprotec (2002) e lasp (2015), apontam para esse aspecto. Nesse sentido, o parâmetro foi incluído ao componente do framework.

Depois que todos os parâmetros foram analisados, percebeu-se que o parâmetro valor estava sendo duplamente analisado. Existia um questionamento no fluxograma "O fator competitivo representa valor para o cliente?" e o próprio parâmetro. Foi perguntado aos especialistas o que eles entendiam por "valor" no contexto de parques e verificou-se que o mesmo representava o aumento da competitividade do mesmo e das empresas instaladas. Analisando essa percepção e o objetivo do parâmetro (analisa o grau em que o fator crítico de sucesso aumenta a competitividade dos clientes de um parque), constatou-se que o parâmetro valor estava mencionado em um contexto macro. Logo, o parâmetro foi removido e o questionamento do fluxograma foi mantido.

Por fim, os especialistas concordaram que os parâmetros distinção, durabilidade, inimitabilidade, combinação e inovação poderiam ser usados no contexto de parques e, por isso, eles foram mantidos no componente. Os parâmetros sofreram refinamentos sucessivos devido às análises das entrevistas, conforme ilustrado na Figura 2:

Figura 2 - Modificações dos parâmetros

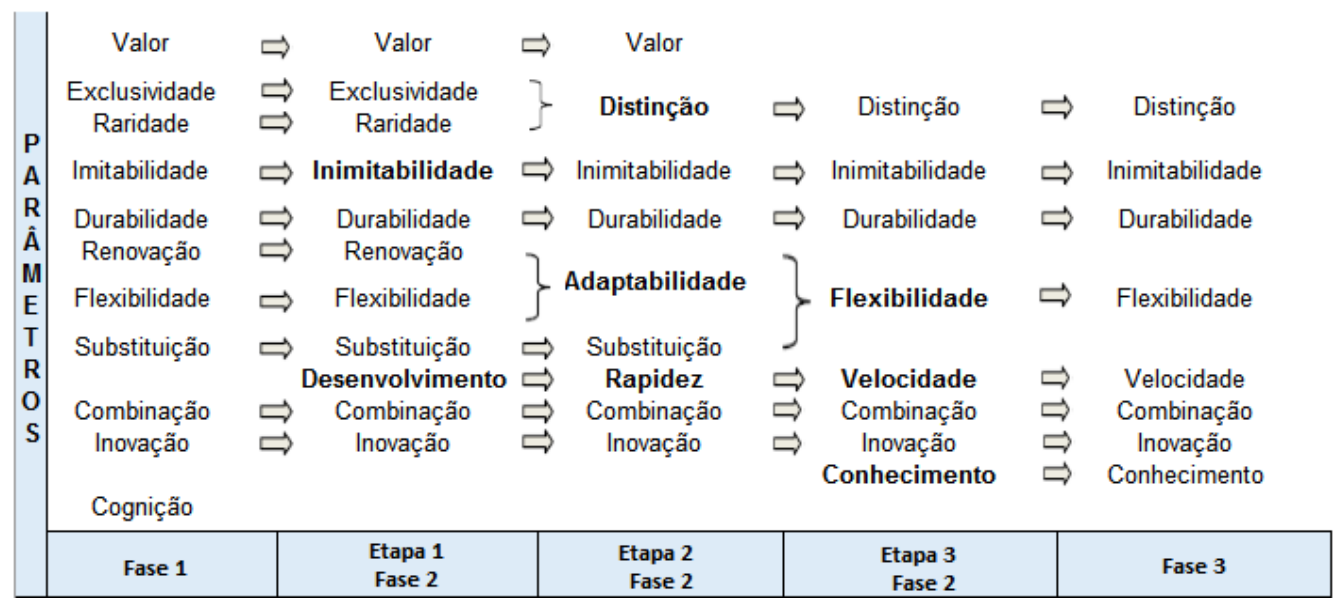

Fonte: Dados da pesquisa (2016)

Uma vez finalizada a etapa de revisão e refinamento do framework pelos especialistas de parques, desenvolveram-se os níveis das escalas de análise para os parâmetros.

Perspectivas em Gestão \& Conhecimento, João Pessoa, v. 9, n. 2, p. 128-152, maio/ago. 2019. 


\subsection{Desenvolvimento das escalas de análise}

Para completar o framework, o objetivo desta fase foi desenvolver as escalas de análise para os parâmetros, considerando as interpretações dos comentários e das sugestões feitas nas etapas anteriores. A seguir estão detalhados o objetivo e a escala de análise de cada um dos parâmetros resultantes dos refinamentos anteriormente descritos.

Distinção - tem por objetivo analisar o quanto um fator crítico de sucesso está presente de modo distintivo no parque. 0 nome do parâmetro foi sugerido pelos especialistas consultados para o contexto de parques, mas originalmente propostos por Heene e Sanchez (1997), Mills et al. (2002), Ljungquist (2007) e Campbell (2008), como características de exclusividade e raridade, necessárias à competitividade. A Figura 3 representa as escalas de análise para o parâmetro distinção.

Figura 3 - Escala de análise para o parâmetro Distinção

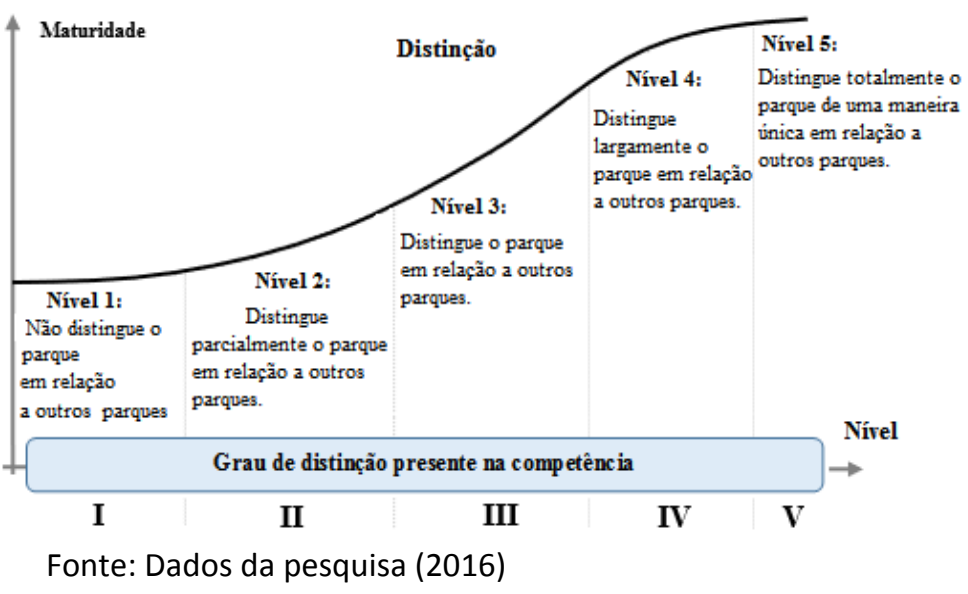

Inimitabilidade - tem por objetivo analisar o grau de dificuldade enfrentado ao tentar imitar um fator crítico de sucesso de um parque. Prahalad e Hamel (1990), Heene e Sanchez (1997), Pettz (1997) e Teece, Pisano e Shuen (1997) e Hitt, Ireland e Hoskisson. (2009) contribuem para o parâmetro e apontam a inimitabilidade como característica importante ao aumento da competitividade das organizações. A Figura 4 representa as escalas de análise para o parâmetro inimitabilidade.

Figura 4 - Escala de análise para o parâmetro Inimitabilidade

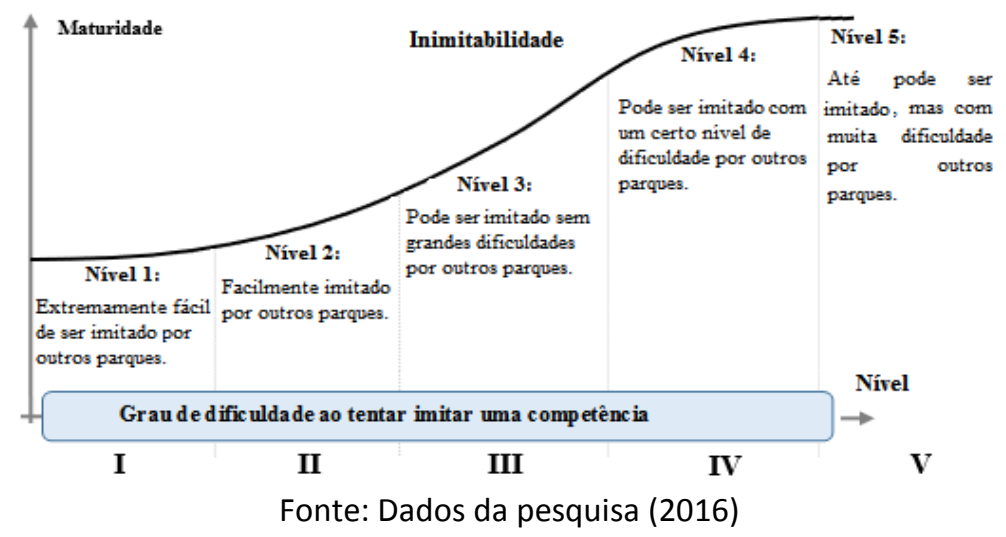

Perspectivas em Gestão \& Conhecimento, João Pessoa, v. 9, n. 2, p. 128-152, maio/ago. 2019. 
Durabilidade - tem por objetivo analisar o quão durável é um fator crítico de sucesso do parque, que gera competitividade para ele e para seus stakeholders. Pettz (1997), Javidan (1998) e Ljungquist (2007) contribuem para o parâmetro e apontam a característica de durabilidade como forma de sustentar a organização em um patamar de competitividade. Nos parques, essa característica é observada nas relações de cooperação, colaboração e competição, que devem existir entre os stakeholders (GARGIONE; LOURENÇÃO; PLONSKI, 2006). A Figura 5 representa as escalas de análise para o parâmetro durabilidade.

Figura 5 - Escala de análise para o parâmetro Durabilidade

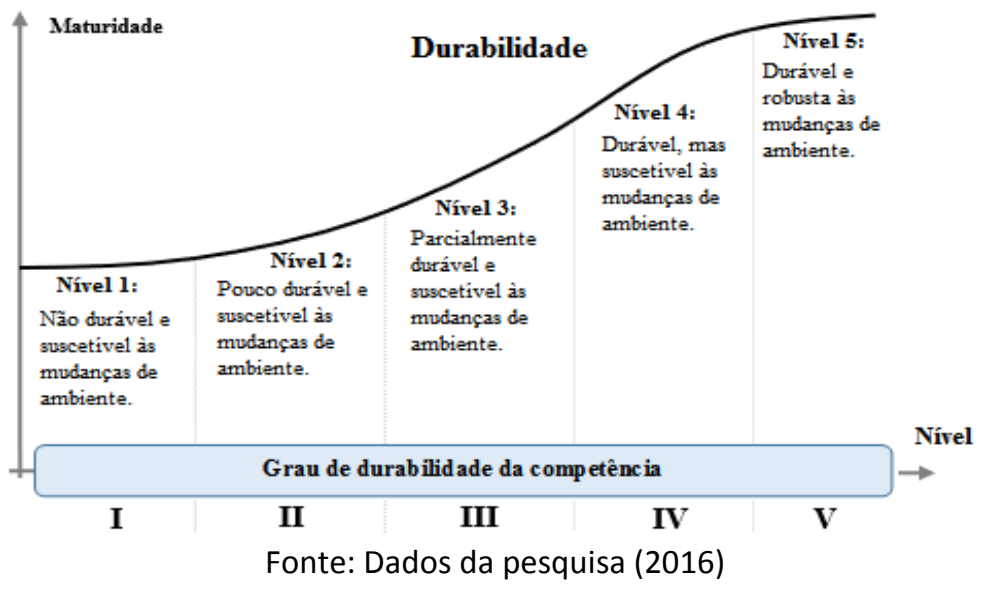

Flexibilidade - tem por objetivo analisar a capacidade do fator crítico de sucesso em se adaptar frente às novas demandas dos stakeholders do parque e do mercado. Esse parâmetro é fundamental no contexto estudado, visto que um parque estabelece relações com diferentes tipos de stakeholders. Ter um modelo de flexibilidade econômico-financeiro é importante para a sobrevivência de um parque, assim como desenvolver novos recursos e reconhecer possibilidades emergentes para definir novos produtos e serviços (PRAHALAD; HAMEL, 1990; BARNEY, 1991; PETTS, 1997; TEECE; PISANO; SHUEN, 1997; JAVIDAN, 1998; HAFEEZ; ZHANG; MALAK, 2002; MILLS et al., 2002; SANCHEZ, 2004). A Figura 6 representa as escalas de análise para o parâmetro flexibilidade.

Figura 6 - Escala de análise para o parâmetro Flexibilidade

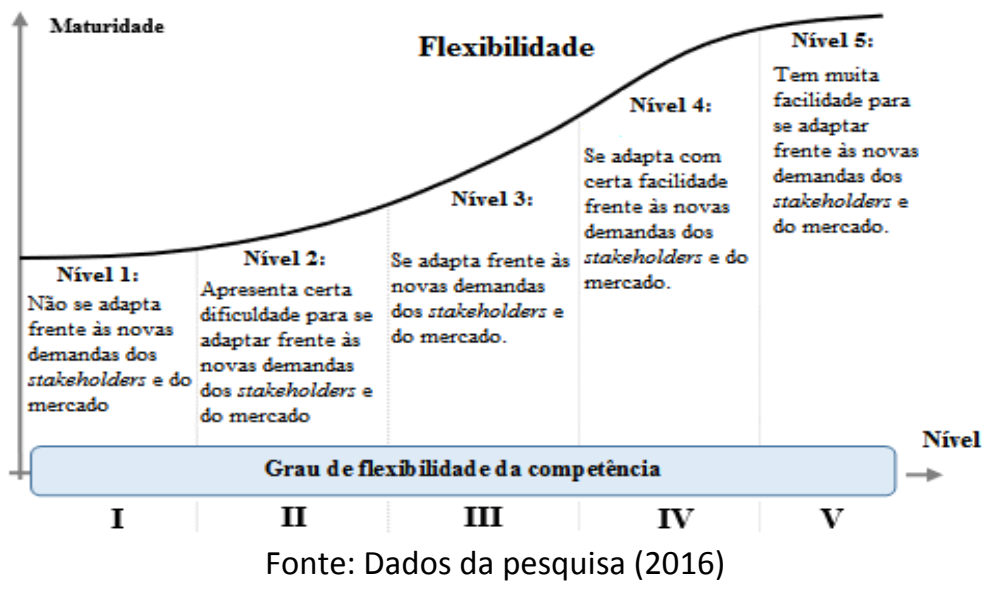

Perspectivas em Gestão \& Conhecimento, João Pessoa, v. 9, n. 2, p. 128-152, maio/ago. 2019. 
Velocidade - tem por objetivo analisar o tempo necessário para um parque adquirir um fator crítico de sucesso que ainda não possui. Para ser competitivo, é preciso adquirir habilidades em um tempo menor que o concorrente. Além disso, quem chegar primeiro ao mercado pode criar barreiras para limitar a mobilidade dos competidores e, assim, aumentar o custo deles (HEENE; SANCHEZ, 1997). A Figura 7 representa as escalas de análise para o parâmetro velocidade.

Figura 7 - Escala de análise para o parâmetro Velocidade

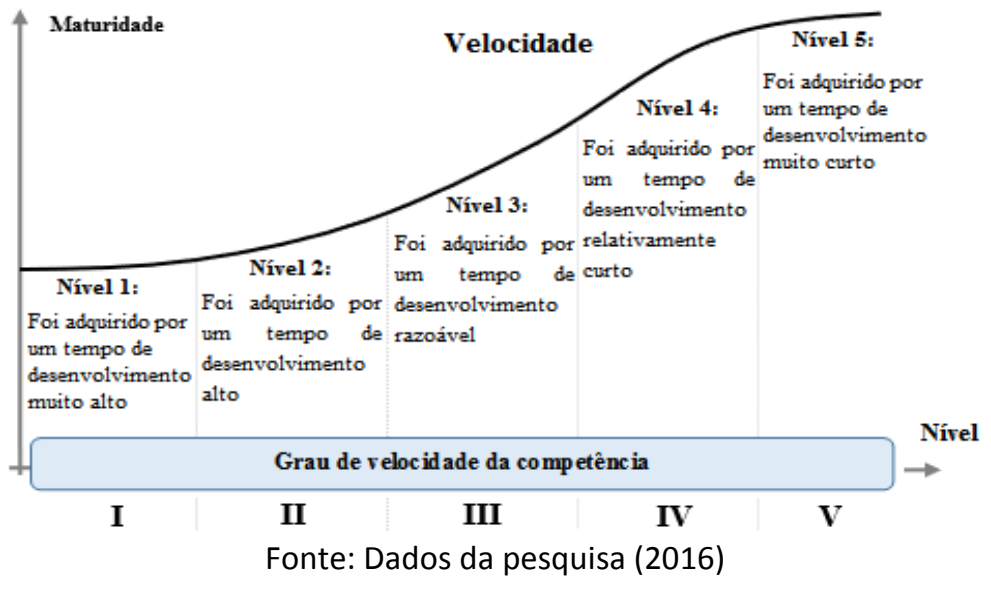

Combinação - tem por objetivo analisar a facilidade de um fator crítico de sucesso em ser combinado com outros ou com recursos disponíveis para atender a uma nova demanda dos stakeholders do parque e do mercado. Combinar os recursos disponíveis para atender às novas demandas é uma maneira do parque estar preparado para desenvolver novos FCS e conseguir atender a essas demandas de uma maneira eficiente (TEECE; PISANO; SHUEN, 1997; MILLS et al., 2002; RUAS, 2005). A Figura 8 representa as escalas de análise para o parâmetro combinação.

Figura 8 - Escala de análise para o parâmetro Combinação

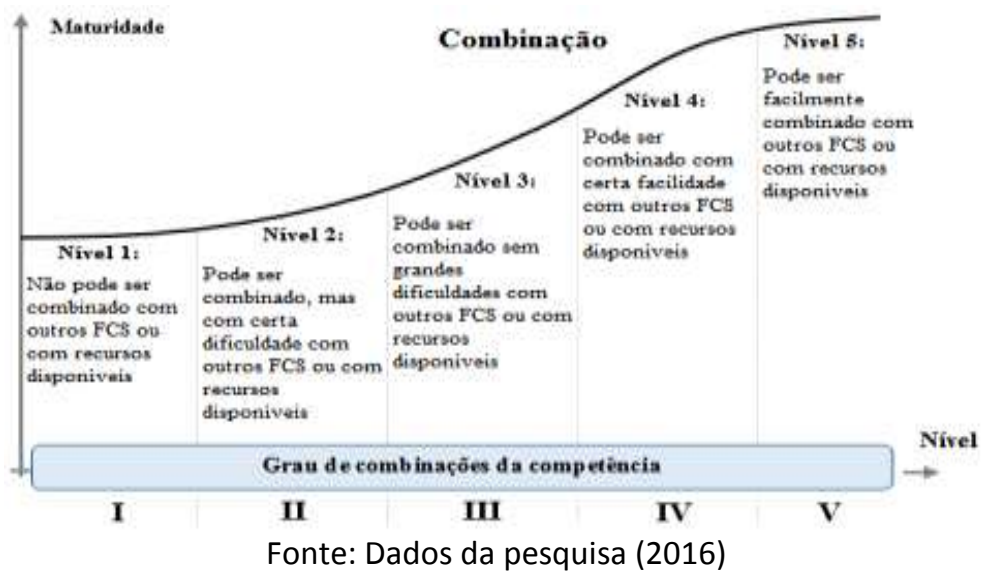

Inovação - tem por objetivo analisar a capacidade do fator crítico de sucesso em fomentar a criação de novos produtos e tecnologias entre os stakeholders do parque. A inovação é uma característica vista como importante, tanto para autores de competências organizacionais, Penrose (1959), Prahalad e Hamel (1990), Petts (1997), Teece, Pisano e Shuen

Perspectivas em Gestão \& Conhecimento, João Pessoa, v. 9, n. 2, p. 128-152, maio/ago. 2019. 
(1997), Danneels (2002) e Mills et al. (2002), quanto para trabalhos específicos sobre parques, tais como Anprotec (2002), Unesco e lasp (2015). A Figura 9 representa as escalas de análise para o parâmetro inovação.

Figura 9 - Escala de análise para o parâmetro Inovação

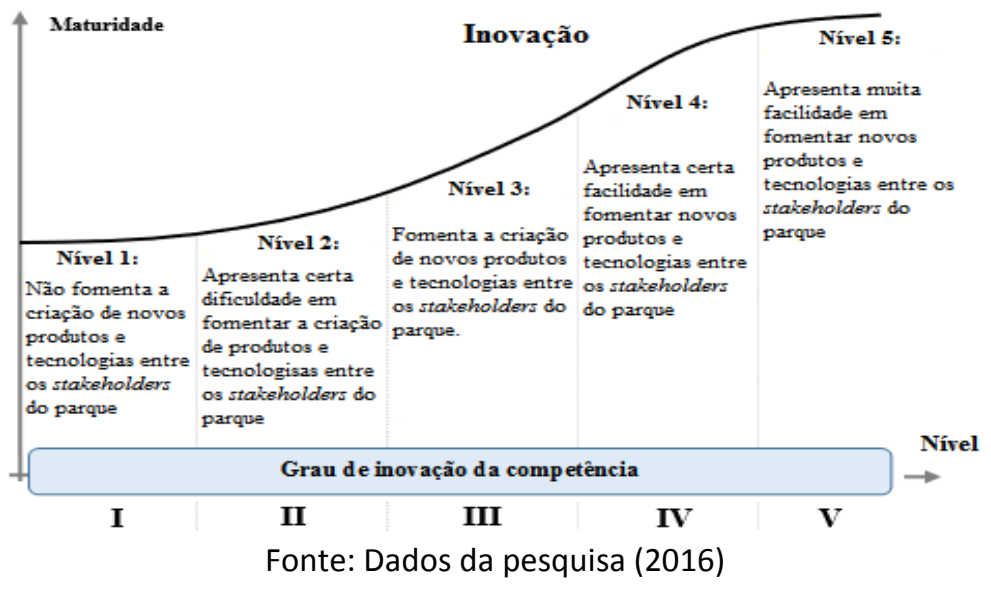

Conhecimento - tem por objetivo analisar a facilidade de um fator crítico de sucesso realizar fluxos de trocas de informações entre os stakeholders do parque. A característica do parâmetro é apontada pelos autores consultados, Prahalad e Hamel (1990), Javidan (1998) e Ljungquist (2013); associações de PCT, Anprotec (2002) e lasp (2015); e autores de parques, Manella (2009). Trata-se de uma característica importante para ser avaliada nos FCS de parques. A Figura 10 representa as escalas de análise para o parâmetro conhecimento.

Figura 10 - Escala de análise para o parâmetro Conhecimento

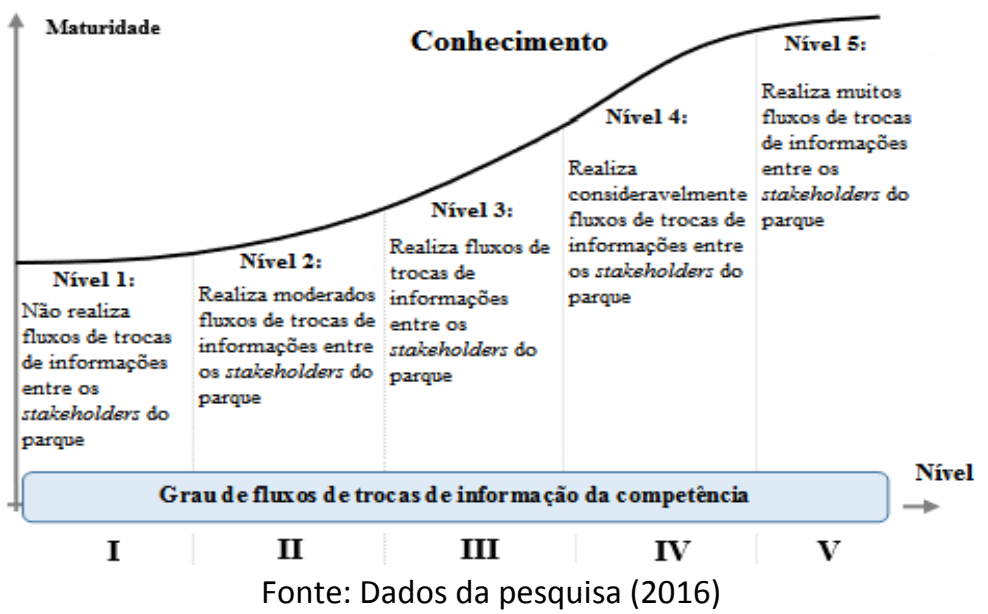

Uma vez que as escalas de análise foram desenvolvidas, elas devem ser refinadas para que se perceba uma correspondência entre as mesmas e o entendimento dos especialistas (MAIER; MOULTRIE; CLARKSON, 2012). 


\section{COMPONENTES DO FRAMEWORK}

A seguir, apresentam-se as versões refinadas dos componentes do framework: os fatores competitivos de parques e o fluxograma de identificação dos FCS de PCT. Esses componentes constituem o processo de identificação dos FCS de PCT, bem como os parâmetros e as escalas de análise, que constituem o processo de avaliação dos FCS de PCT.

\subsection{Fatores competitivos}

Após os refinamentos sofridos pelos especialistas, apresenta-se a versão final do componente fatores competitivos de parques, o qual está mostrado no Quadro 3:

Quadro 3-Categorias e fatores competitivos

\section{INFRAESTRUTURA}

- Ter infraestrutura física local e ou distribuída para a instalação de empresas e atuação de seus stakeholders.

- Ter infraestrutura que forneça um ambiente de interação e de qualificação para seus stakeholders.

- Ter infraestrutura tecnológica favorável à difusão do conhecimento e que seja compartilhada com universidade(s) e institutos de pesquisa.

- Ter infraestrutura de transporte de fácil acesso, conectada a centros tecnológicos, institutos de pesquisa e universidade(s) da região.

- Ter infraestrutura que forneça uma rede de serviços auxiliares, como: restaurante, posto médico, bancos, farmácia, etc. e que proporcione qualidade de vida para as pessoas.

AMBIENTE DE INOVAÇÃO E EMPREENDEDORISMO

- Ter presença de empresas instaladas, incubadoras ou aceleradoras como forma de atração para novas candidatas.

- Fomentar uma cultura de inovação e empreendedorismo que produza propriedade intelectual.

- Ter dinamismo focado em mudanças de cunho tecnológico e nos relacionamentos pessoais e organizacionais.

- Apresentar diversidade tanto de tamanho como de segmento de empresas instaladas.

- Ser um ambiente propício para a interação entre as pessoas e as empresas, como coworking, eventos, palestras, conferências, seminários etc.

\section{GESTÃO E GOVERNANÇA DO PARQUE}

- Ser gerido como um negócio com foco voltado para as necessidades dos seus stakeholders e shareholders.

- Ter uma gestão executiva ou conselho de administração e ou conselho de gestores experientes para definir questões estratégicas e operacionais do parque ao longo prazo e que tenha agilidade, alto grau de independência, dinamicidade, criatividade, autonomia e rapidez nos processos de tomada de decisão.

- Ser integrado nos planos de desenvolvimento sustentável da região sob o ponto de vista financeiro, social e ambiental.

- Ter uma gestão com processos administrativos sistematizados e flexíveis para atender as demandas do mercado e de seus stakeholders.

- Ter um modelo de gestão com destaque para a responsabilidade social, econômica e ambiental do empreendimento.

\section{FATORES ECONÔMICOS E FINANCEIROS}

- Ter um modelo de sustentabilidade econômica e financeira para gerar recursos de reinvestimento no mesmo.

- Ter flexibilidade na modelagem econômico-financeira para atração de novos investimentos.

- Facilitar o acesso aos recursos financeiros por parte do setor privado por meio de seed capital, angel capital e venture capital.

Perspectivas em Gestão \& Conhecimento, João Pessoa, v. 9, n. 2, p. 128-152, maio/ago. 2019. 
- Captar recursos financeiros via agências de fomento em pesquisa, desenvolvimento e inovação.

\section{SERVIÇOS TÉCNICOS ESPECIALIZADOS}

- Fomentar consultorias em planejamento estratégico, planos de negócios, gestão empresarial em marketing, vendas, finanças e administração de recursos humanos e de gestão da inovação.

- Fomentar a geração de profissionais especializados e oportunidades de trabalho qualificados.

- Conectar núcleos especializados em serviços de tecnologia e inovação.

- Ofertar serviços de consultoria especializada para atender seus stakeholders.

- $\quad$ Fomentar programas de mentoria, capacitação e desenvolvimento profissional.

\section{INTERAÇÃO UNIVERSIDADE-EMPRESA-GOVERNO}

- $\quad$ Promover e formar redes de cooperação entre empresas e universidade(s) para pesquisa e desenvolvimento de inovação tecnológica.

- Estabelecer relacionamentos com universidade(s) e institutos de pesquisa que desenvolvam pesquisas de relevância empresarial.

- Garantir acesso das empresas à base de conhecimento da(s) universidade(s) para desenvolver pesquisas e projetos em conjunto e promover a disponibilização e transferência do conhecimento acadêmico.

- Garantir acesso das empresas aos pesquisadores, aos professores e aos profissionais provenientes de universidade(s) e de instituições de ensino e pesquisa.

- Ter laboratórios e equipamentos compartilhados com as empresas e universidade(s) de forma a evitar investimentos duplicados ou facilitar a acesso de seus stakeholders. MERCADOLÓGICOS

- $\quad$ Ser um canal para a internacionalização de empresas que estão nele.

- Procurar estabelecer convênios de cooperação com outros parques, com universidade(s) e com institutos de pesquisa.

- Facilitar o acesso a mercados no setor de atuação das empresas interessadas em se estabelecerem no parque.

- $\quad$ Sinalizar oportunidades de negócio para seus stakeholders. ASPECTOS COMPORTAMENTAIS E PESSOAIS

- Atuar no cenário global, mas respeitando as características e a cultura locais.

- Ter familiaridade cultural com a região em que está localizado.

- Entender os diferentes valores culturais e linguísticos das pessoas que fazem parte dele, como crenças, percepções, opiniões e atitudes.

Fonte: Dados da pesquisa (2016)

\subsection{Fluxograma de identificação de FCS de PCT}

Após os refinamentos sofridos pelos especialistas, apresenta-se a versão final do componente fluxograma de identificação de FCS de PCT o qual está mostrado na Figura 12. 
Figura 12 - Fluxograma de identificação de FCS de PCT

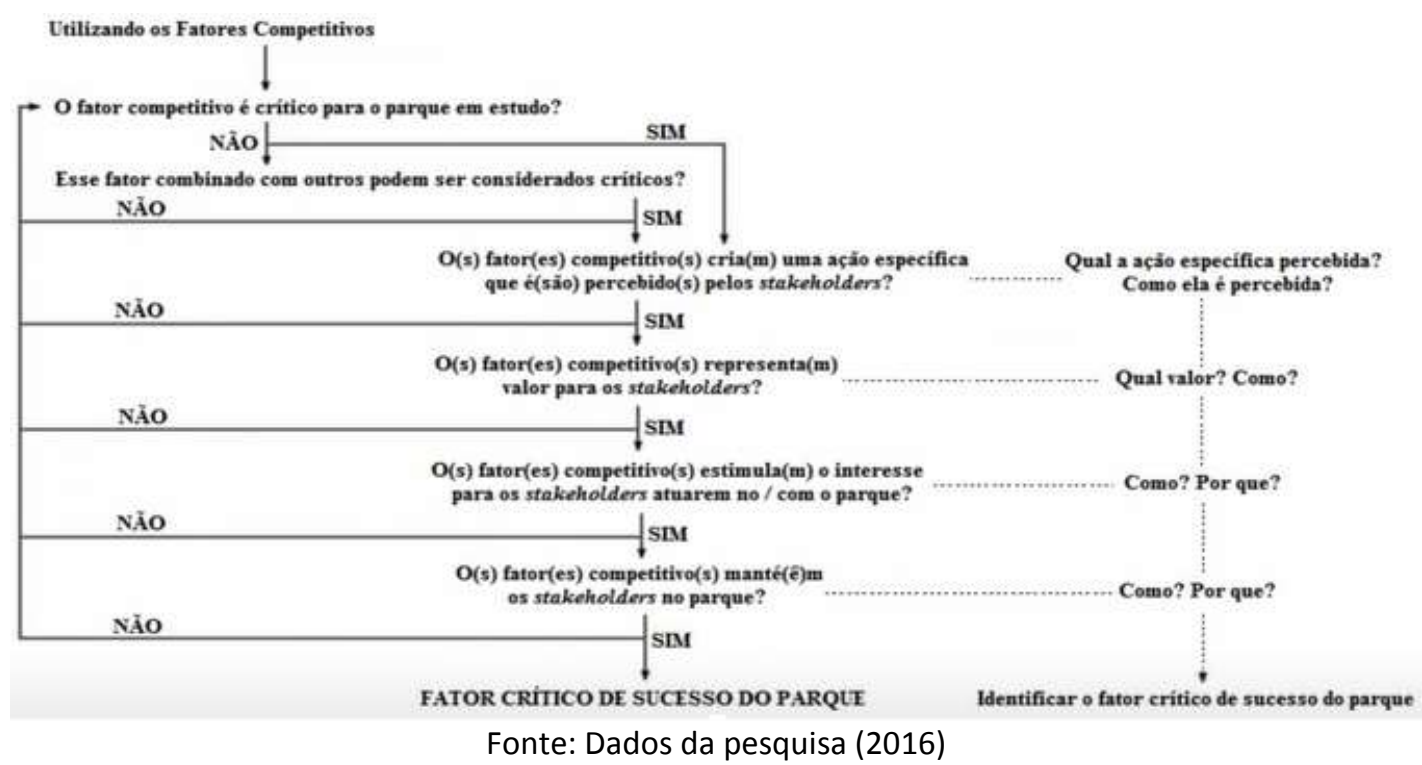

\subsection{Parâmetros e escalas de análise}

Depois de identificados, os FCS devem ser avaliados pelos parâmetros e pelas escalas de análise que foram criadas para cada um deles. O objetivo da avaliação é verificar o quanto presentes e perceptíveis os parâmetros estão nos FCS identificados. Cada parâmetro deve ser cuidadosamente analisado para cada fator crítico de sucesso identificado. Os parâmetros são características importantes que devem ser observadas nos FCS de parques. Sugere-se que uma maior presença observável desses parâmetros, mais valor ela gera para os stakeholders que fazem parte do parque analisado.

A Tabela 1 relaciona os parâmetros sugeridos por este artigo com os FCS que são identificados pelo fluxograma de identificação de FCS de parques. Esta tabela deve ser aplicada tanto nos gestores de parques, como nos gestores das empresas instaladas nos mesmos para verificar se a percepção do primeiro é ratificada ou retificada em relação ao segundo.

Portanto, os gestores de parques e das empresas instaladas devem identificar se cada parâmetro é aplicável ou não para cada fator crítico de sucesso identificado. Se sim, eles devem analisar em qual nível da escala de análise aquele parâmetro é observado no fator crítico de sucesso. As escalas de análise para cada parâmetro estão mostradas nas Figuras 3 a 10. Cada análise de parâmetro é composta, também por uma pergunta que o gestor deve responder ao analisar a escala de análise de cada parâmetro. Essa resposta ajuda no processo de análise dos resultados. Se o parâmetro não for aplicável no fator crítico de sucesso, deve se usar o valor NA (não aplicável).

Tabela 1 - Avaliação dos parâmetros e escalas de análise

\begin{tabular}{c|c|c|c|c|c}
\hline FCS & F1 & F2 & F3 & F4 & F5 \\
\hline Escalas & $\begin{array}{c}1,2,3,4,5 \text { ou } \\
\text { NA }\end{array}$ & $\begin{array}{c}1,2,3,4,5 \text { ou } \\
\text { NA }\end{array}$ & $\begin{array}{c}1,2,3,4,5 \text { ou } \\
\text { NA }\end{array}$ & $\begin{array}{c}1,2,3,4,5 \text { ou } \\
\text { NA }\end{array}$ & $\begin{array}{c}1,2,3,4,5 \text { ou } \\
\text { NA }\end{array}$ \\
\hline Parâmetros & Distinção & & & & \\
\hline Inimitabilidade & & & & & \\
\hline Durabilidade & & & & & \\
\hline Flexibilidade & & & & & \\
\hline
\end{tabular}

Perspectivas em Gestão \& Conhecimento, João Pessoa, v. 9, n. 2, p. 128-152, maio/ago. 2019. 


\begin{tabular}{c|l|l|l|l|l}
\hline Velocidade & & & & & \\
\hline Combinação & & & & & \\
\hline Inovação & & & & & \\
\hline Conhecimento & & & & & \\
\hline
\end{tabular}

Fonte: Dados da pesquisa (2016)

*Legenda: O nível mínimo é 1 e o máximo é 5. NA (não aplicável)

\section{CONSIDERAÇÕES FINAIS}

O framework proposto é formado por dois processos com objetivos complementares. O primeiro deles identifica os FCS de parques por meio dos componentes: fatores competitivos de parques e fluxograma de identificação de FCS de parques. Uma vez que os fatores competitivos do parque em análise foram identificados, partiu-se para a verificação se aquele fator era crítico para o mesmo, considerando a análise do segundo componente proposto. Um ou mais fatores competitivos podem representar um fator crítico de sucesso para o parque. Não existe uma relação de 1:1 entre os fatores. Portanto, as repostas das entrevistas devem ser analisadas cuidadosamente para que os FCS sejam corretamente identificados.

Avaliou-se os FCS de parques pelos parâmetros e pelas respectivas escalas de análise, que foram criadas para cada um deles. Os parâmetros representam as características de parques, que devem ser observadas nos FCS identificados. Nesse caso, as escalas tinham a função de auxiliar na percepção do grau em que um determinado parâmetro é observado no FCS. Durante o desenvolvimento do framework proposto, observou-se um desafio acadêmico. Ao utilizar o contexto de competitividade em parques, foi necessário fazer adaptações, pois os parques são (em sua maioria) organizações sem fins lucrativos, ligados às universidades e às mantenedoras, bem como um espaço de convivência, cooperação e integração entre o ambiente empresarial e o ambiente acadêmico (COURSON, 1997; ETZKOWITZ, 2003).

Este estudo permitiu identificar que a competição entre parques existe quando eles disputam algum recurso público de interesse por meio dos editais publicados pelos órgãos de fomento; e quando algum parque anseia pela presença de alguma empresa para ser integrada ao seu ecossistema (ANPROTEC, 2002). Portanto, entender o contexto da competitividade e construir os componentes do framework proposto no contexto de parques representaram uma contribuição deste artigo.

Os quatro componentes dos processos de identificação e avaliação de FCS de parques são contribuições acadêmicas, pois enfatizam os problemas apontados pelos autores de parques, como: dificuldades metodológicas nos processos de avaliação de parques (VEDOVELLO; JUDICE; MACULAN, 2006); e falta de evidências empíricas com relação aos fatores que são críticos para a implantação e desenvolvimento de um parque (VEDOVELLO, 2000; LÖFSTEN; LINDELÖF, 2005). Além disso, as contribuições deste trabalho enriquecem a troca de conhecimento com a academia, pois promovem, estimulam e convidam novos investigadores a se interessarem pelo tema e proporem futuras pesquisas.

Para que o framework proposto consiga identificar as semelhanças e as idiossincrasias de percepções dos stakeholders dos parques, o mesmo deve ser aplicado em gestores de parques, assim como em gestores de empresas instaladas nos mesmos. Comparar as diferentes percepções de gestores que coabitam um espaço de colaboração, inovação, pesquisa e desenvolvimento é de fundamental importância para que gestores de parques possam priorizar ações corretivas e criar sinergia, colaboração, cooperação e inovação entre os stakeholders.

Perspectivas em Gestão \& Conhecimento, João Pessoa, v. 9, n. 2, p. 128-152, maio/ago. 2019. 


\section{REFERÊNCIAS}

ANPROTEC. Glossário dinâmico de termos na área de Tecnópolis. Parques tecnológicos e incubadoras de empresas: Brasília, 2002. Disponível em: http://www.anprotec.org.br/ArquivosDin/GLOSSARIO pdf 12.pdf

AURP (Association of University Research Parks). What is a research park? 2016. Disponível em: http://www.aurp.net/what-is-a-research-park

BARDIN, L. Análise de conteúdo. Lisboa: Edições 70, 2006.

BARNEY, J. Firm resources and sustained competitive advantages. Journal of Management, $n$. 17, v.1, p. 99-120, 1991.

BIGLIARDI, B. et al. Assessing science parks performances: directions from selected Italian case studies. Elsevier. Technovation, n. 26, v. 4, p. 489-505, 2006.

BOLTON, W. The university handbook on enterprise development. Paris: Columbus Handbooks, 1997.

BROTHERTON, B.; SHAW, J. Towards an identification and classification of critical success factors in UK hotels plc. International Journal of Hospitality Management, v. 15 n. 2, p. 11335, 1996.

CAMPBELL, J. T. et al. The dynamic interlay of capability strengths and weaknesses: investigating the bases of temporary competitive advantage. Strategic Management Journal, n. 31, p. 1386-1409, 2008.

CHEN, H. M.; CHANG, W. Y. The essence of the competence concept: adopting an organization's sustained competitive advantage viewpoint. Journal of Management Organization, n. 16, p. 677-699, 2010.

COURSON, J. Espaço urbano e parques tecnológicos europeus. In: PALADINO, G. G.; MEDEIROS, L. A. Parques tecnológicos e meio urbano. Brasília: ANPROTEC, 1997.

DANNEELS, E. The dynamics of product innovation and firm competences. Strategic Management Journal, n. 23, p. 1095-1121, 2002.

EISENHARDT, K. M.; SANTOS, F. M. Knowledge-based view: a new theory of strategy. In: PETTIGREW, A.; THOMAS, H.; WHITTINGTON, R. Handbook of strategy and management. London: Sage, 2002. p. 139-164.

ETZKOWITZ, H. The norms of entrepreneurial science: cognitive effects of the new universityindustry linkages. Research Policy, n. 27, p. 823-833, 1998.

FERRAZ, J.C.; KUPFER, D.; HAGUENAUER, L. Competitividade, padrões de concorrência e fatores determinantes. Made in Brazil: desafios contemporâneos para a indústria. 2.ed. Rio de Janeiro: Campus, 1997.

Perspectivas em Gestão \& Conhecimento, João Pessoa, v. 9, n. 2, p. 128-152, maio/ago. 2019. 
GARGIONE, L. A. Um modelo para financiamento de parques tecnológicos no Brasil: explorando o potencial dos fundos de investimento. Tese (Doutorado em Engenharia). Escola Politécnica da Universidade de São Paulo, São Paulo. 345f. 2011. Disponível em: http://www.teses.usp.br/teses/disponiveis/3/3136/tde-12082011-

110544/publico/Tese_Luiz_A_Gargione.pdf

GARGIONE, L. A.; LOURENÇÃO, P. T. M. Fatores críticos de sucesso para modelagem de parques tecnológicos privados no Brasil. In: SEMINÁRIO LATINO-IBERO-AMERICANO DE GESTIÓN TECNOLÓGICA, 11., 2005, Salvador. Anais [...] Salvador: [s.n.], 2005.

GARGIONE, L. A.; LOURENÇÃO, P. T. M.; PLONSKI, G. A. Elementos críticos para modelagem de parques tecnológicos privados no Brasil. In: SIMPÓSIO DE GESTÃO DA INOVAÇÃO TECNOLÓGICA, 24., 2006, Gramado. Anais [...] Gramado: [s.n.], 2006.

GRUNERT, K. G.; ELLEGAARD, C. The concept of key success factors: theory and method. MAPP Working Paper, n. 4, p.1-28, oct. 1992.

HAFEEZ K.; ZHANG Y.; MALAK N. Core competence for sustainable competitive advantage: a structured methodology for identifying core competence. IEEE. Transactions on Engineering Management, v. 49, n.1, p.28-35, 2002.

HEENE, A.; SANCHEZ, R. Competence-based strategic management. The Strategic Management Series. p.65-84, 1997.

HELFAT, C. E.; PETERAF, M. A. The dynamic resource-based view: capabilities lifecycles. Strategic Management Journal, v. 24, n.10, p. 997-1010, 2003.

HITT, M. A.; IRELAND, R. D; HOSKISSON, R. E. Ambiente interno: recursos, capacitações e competências essenciais. In: HITT, M. A.; IRELAND, R. D; HOSKISSON, R. E. Administração estratégica. São Paulo: Cengage Learning, 2009. p. 77-96.

IASP (International Association of Science Parks and Areas of Innovation). Knowledge bites. 2015. Disponível em: http://www.iasp.ws/knowledge-bites

JAVIDAN, M. Core Competence: What Does It Mean in Practice? Long Range Planning, v. 31, n. 1, p. 60-71, 1998.

LEITE, J. B. D.; PORSSE, M. C. S. Competição baseada em competências e aprendizagem organizacional: em busca da vantagem competitiva. In: RUAS, R.; ANTONELLO, C. S.; BOFF, L. H. Os novos horizontes da gestão: aprendizagem organizacional e competências. Porto Alegre: Bookman, 2005. p. 56-70.

LINK, A. N.; SCOTT, J. T. The economics of university research parks. Oxford Review of Economic Policy, v. 23, n. 4, p. 661-674, 2007.

LUNGQUIST, U. Adding dynamics to core competence concept applications. European Business Review, v. 25, n. 5, p. 453-465, 2013.

Perspectivas em Gestão \& Conhecimento, João Pessoa, v. 9, n. 2, p. 128-152, maio/ago. 2019. 
LUNGQUIST, U. Core competency matters: preparing for a new agenda. Acta Wexionensia. Business Administration, Växjö University Press, Sweden, v. 121, p. 1-78, 2007.

LÖFSTEN, H.; LINDELÖF, P. R\&D networks and product innovation patterns: academic and nonacademic new technology-based firms on science parks. Techovation, n. 25, p. 1025-1037, 2005.

MAIER, A. M.; MOULTRIE, J.; CLARKSON, P. J. Assessing organizational capabilities: reviewing and guiding the development of maturity grids. IEEE Transactions and Engineering Management, v. 59, n. 1, p. 138-159, 2012.

MANELLA, B. F. P. Fatores de atratividade de empresas inovadoras para parques tecnológicos. Dissertação (Mestrado em Administração). Faculdade de Economia, Administração e Contabilidade, Universidade de São Paulo, Ribeirão Preto, 2009.

MILLS, J. et al. Strategy and performance: competing through competences. Cambridge: Cambridge University Press, 2002.

MINTZBERG, H. Ajustando o design à situação. In: MINTZBERG, H. Criando organizações eficazes. São Paulo: Atlas, 2003. p. 140-171.

PENROSE, E. The theory of the growth of the firm. Oxford: Basil Blackwell, 1959.

PETTS, N. Building growth on core competences: a practical approach. Long Range Planning, v. 30, n. 4, p. 551-561, 1997.

PRAHALAD, C. K.; HAMEL, G. The core competence of the corporation. Harvard Business Review, v. 68, n. 3, p. 79-90, 1990.

ROCKART, J. F. Chief executive define their own data needs. Harvard Business Review, Boston, v. 57, n. 2, p.81-93, mar. 1979

RUAS, R. Gestão por competências: uma contribuição à estratégia das organizações. In: RUAS, R.; ANTONELLO, C. S.; BOFF, L. H. Os novos horizontes da gestão: aprendizagem organizacional e competências. Porto Alegre: Bookman, 2005. p. 34-54.

SAMPIERI, R. H. O processo de pesquisa e enfoque quantitativo e qualitativo: rumo a um modelo integral. In: SAMPIERI, R. H.; COLLADO, C. H.; LUCIO, P.B. Metodologia de pesquisa. 3.ed. São Paulo: McGraw-Hill, 2006. p. 3-17.

SANCHEZ, R. Understanding competence-based management. Identifying and managing five modes of competence. Journal of Business Research, v. 57, n. 5, p. 518-532, 2004.

SLUYTIS, K. et al. Building capabilities to manage strategic alliances. In: THE 26TH IMP CONFERENCE, Budapeste, 2010. p. 1-24. Disponível em: https://pdfs.semanticscholar.org/c676/d2ac4936cf60d136fe08bbd1f7a789a77dd8.pdf

SPOLIDORO, R.; AUDY, J. Parque científico e tecnológico da PUCRS. Porto Alegre: ediPUCRS, 2008.

Perspectivas em Gestão \& Conhecimento, João Pessoa, v. 9, n. 2, p. 128-152, maio/ago. 2019. 
TECNOPUC. Institucional. 2015. Disponível em:

http://www3.pucrs.br/portal/page/portal/inovapucrs/Capa/Tecnopuc/Institucional

TEECE, D. J.; PISANO G.; SHUEN, A. dynamic capabilities and strategic management. Strategic Management Journal, v. 18, n. 7, p. 509-533, 1997.

UNESCO (Organização das Nações Unidas para a Educação, Ciência e Cultura). Science policy and capacity-building: concept and definition. 2015. Disponível em: http://www.unesco.org/new/en/natural-sciences/science-technology/university-industrypartnerships/science-and-technology-park-governance/concept-and-definition/

VÁSQUEZ-URRIAGO, A. R. et al. The impact of science and technology parks on firms product innovation: empirical evidence from Spain. Journal of Evolutionary Economics, v. 24, n. 4. p. 835-873, 2014.

VARGAS, C. A. F.; RECH, I.; SANTOS, S. A. Fatores de competitividade empresarial em empresas instaladas em um parque tecnológico brasileiro. Revista de Gestão \& Tecnologia, v. 16, n. 2, p. 100-126, 2016.

VEDOVELLO, C. A. Aspectos relevantes de parques tecnológicos e incubadoras de empresas. Revista do BNDES, Rio de Janeiro, v.7, n. 14, P. 273-300, 2000.

VEDOVELLO, C. A.; JUDICE, V. M. M.; MACULAN, A. D. Revisão crítica às abordagens a parques tecnológicos: alternativas interpretativistas às exigências Brasileiras recentes. RAI - Revista de Administração e Inovação, v. 3, n. 2, p. 103-118, 2006.

VIAL, I. D., OLMOS, M. F. Knowledge spillover in science and technology parks: how can firms benefit most? The Journal of Technology Transfer, v. 40, n. 1, p.70-84, 2014.

WERNERFELT, B. A Resource-based view of the firm. Strategic Management Journal, vol. 5, p.171-180, 1984.

WITT, A. Metodologia de pesquisa: questionário e formulário. São Paulo: Editora Resenha Tributária, 1973.

ZAIRI, M. O verdadeiro significado da competição. HSM Management, v. 1, n. 3, p. 86-94, 1997.

ZOUAIN, D. M. Parques tecnológicos propondo um modelo conceitual para regiões urbanas: o parque tecnológico de São Paulo. 261f. 2003. Tese (Doutorado em Ciências) - Faculdade de Ciências na Área de Tecnologia Nuclear - Aplicações, Universidade de São Paulo, São Paulo, 2003. Disponível em: http://www.teses.usp.br/teses/disponiveis/85/85131/tde-27032014134435/publico/2003ZouainParques.pdf.

Artigo recebido em 27/03/2019 e aceito para publicação em 10/08/2019

Perspectivas em Gestão \& Conhecimento, João Pessoa, v. 9, n. 2, p. 128-152, maio/ago. 2019. 